\title{
The Photographic Sensitivity Mechanism - an Unlocked Subject
}

\author{
VLADIMIR CONSTANTIN BACAREA ${ }^{2 *}$, PETRUS FANEL BACAREA ${ }^{2}$, ANCA BACAREA ${ }^{3}$ \\ ${ }^{1}$ UMFST Targu Mures, Medical Scientific Research Methodology Department, 38 Gheorghe Marinescu Str., 540139, Targu Mures, \\ Romania \\ ${ }^{2}$ S.C. Prochiral SRL, 66/16 Gheorghe Marinescu Str., Targu Mures, Romania \\ 3UMFST Targu Mures, Pathophysiology Department, 38 Gheorghe Marinescu Str., 540139, Targu Mures, Romania

\begin{abstract}
The paper aims to demonstrate how a dogma, favored by random experimental discoveries, can change the progress of research. It has been experimentally shown that photographic sensitization is achieved by adsorption of preformed sensitivity centers on AgX granules. The mechanism of classical sensitization can be the emulsion formation of centers concomitant with adsorption on granules.
\end{abstract}

Key words: Photosensitivity, Sensitization center, Nanoparticle, Plasmon, Adsorption on the grain

The present paper proposes an out-of-the-box approach to a phenomenon that is still unclear, the mechanism of photographic sensitivity. This subject, despite the impressive development of research, could notbe resolved until the natural death of the classical photosensitive materials industry and the disappearance of the related interest and explosive market entry of the digital image.

Classical photosensitive materials, based on silver halides and gelatin, have virtually held the image market (photography, cinema, printing industry, medical imaging, non-destructive control with penetrating radiation, recording and archiving of information, television, scientific research etc.) more than 150 years. The field of photosensitive materials has always been considered as a high technology and a very innovative one. Although it stretched over a very long period (more than 150 years) [1], no one can claim to have a complete and clear understanding of the process of image formation and preservation [2]. We try to explain this paradoxical situation not only by the complexity of the physics and chemistry of the process itself, but also by the counterproductive methodological approach of the study.

We will point out a few crucial moments that marked the course of the research. The first purely experimental breakthrough was the use of gelatin for the incorporation of silver halide micro-particles. In addition to the exceptional qualities of protective colloid [3], which made gelatin irreplaceable until the end of classical photosensitive materials, it had a hidden active composition. Some amino-acids in the polypeptide chain contain in the side chains active functions capable of forming complexes with metal ions, or doing reducing, sulfide forming, and condensing reactions. On the other hand, gelatin inevitably contains reducing, sulfide forming or inhibiting impurities from the biogenic material and the manufacturing process [4-6]. The increased sensitivity of the gelatin emulsions [7] opened the way for empirical testing by introducing into the emulsion various materials (some strange ones). Thus, the spectacular effect on the sensitivity of mustard extract, which contains organic sulfur derivatives [8], has been discovered. Later [3] it was found that by introducing dyes into the emulsion, the range of spectral sensitivity increases from natural sensitivity to UV and blue, to green and then to red and infrared, opening the way for chromatic sensitivity and more accurate color rendering in black and white tones. By the 1936s, Koslowski and Mueller [9] discovered gold sensitization by introducing the thiocyanate gold complex into the emulsion.
All of these random experimental discoveries, alongside the spectacular applicative importance, made damage for a clear understanding of the mechanism of photosensitivity. Scientific thinking in the field has entered in the paradigm of introducing into the emulsion various compounds that react to the surface of the grains producing sensitivity or fog centers or chromatic sensitizer aggregates. Thus, Trivelli [10] showed that the art of preparing high sensitivity photographic emulsions can be viewed primarily as the art of introducing impurities into AgX in a particular way, and Sheppard [11] states that sensitization is achieved by forming on the surface of the grains of tiny deposits of silver sulfide produced from the normal sulfur compounds present in gelatin". It is paradoxical, but it has been shown that a single AgX granule sensitivity center, which can provide developability after exposure to light, is composed of several sulfur atoms associated with Ag and / or Au, but optimal sensitization requires about $10^{5}$ sulfur atoms per grain [12]. A great deal of research w ork has been done to clarify the mechanism of sensitization $[13,14]$ and the nature of sensitivity and fog centers [15-19]. Over time, it has crystallized the idea that sensitizing agents introduced into the emulsion are adsorbed to the surface of AgX grains, where they react to form a silver sulfide film, mixed gold and silver sulfide, or a mixture of reduced silver or/and gold and sulfides [20] which then migrates on the surface concentrating into islets, but especially that these centers are formed on the surface defects of the grains [21-24]. J. W. Mitchell is the only one who suggests that sensitivity centers could be located in the gelatin layer adsorbed on the surface of the grains [25].

No one has raised the question that it is possible that the sensitivity and fog centers do not form directly on the surface of the grains, but in the intergranular aqueous medium and, once formed, adhere to the grains. This mechanism is not only possible, but also very likely, since the sulfur precursor micro-flux from the reaction mass to the surface of the grain intersects with that of the silver ions complexes coming from the grain to the reaction mass. The maximum concentration of the two reactants is at a certain distance from the surface of the grain. Then, if so, why not separate this processes of forming the sensitivity centers from that of the actual sensitization achieved by adsorbing them on the grains? Our previous, unpublished research has demonstrated that this mechanism is not only possible, but can also lead to particular application benefits in both fundamental and industrial research. We also appreciate that this approach, given the advances made in the past decades in the field

\footnotetext{
*email: vladimir.bacarea@umftgm.ro, bacarea@gmail.com, Phone:+40744645744
} 
of nanoparticles and plasmons physics [26], could finally explain the issue of the mechanism of photo sensitivity, even if it is only for academic interest.

\section{Experimental part}

In order to demonstrate the before mentioned idea, the chemical sensitization method has been modified. The introduction of the sensitizing agents into the emulsion was abandoned. Sensitivity centers were separately prepared as a colloidal suspension of nanoparticles in gelatin solution. From this suspension, precursors and secondary reaction products have been removed from the suspension. The UV-Vis absorption spectra served as a means for controlling the batch reproducibility.

Sensitizers pretreated by reduction or transformation into sulfides or selenides nanoparticles were applied to desalted emulsions of various types: cubic, cubo-octahedral monodisperse, multistructured, and tabular, precipitated in neutral or ammonia medium.

Optimal working conditions on the sensitizer dose, working temperature and time required by experimental testing were determined, aiming to increase the sensitivity and contrast and keeping the fog at the minimum value.

In view of the very large number of nanoscale suspensions susceptible to application, the great variety of AgX emulsion types, the possibility of being introduced at different growth phases of the AgX micro-grains (the same sensitizer or different sensitizers) and the reaction parameters, in order to restrict the area to a feasible field, we started from the most likely situations, based on the momentary knowledge of the components involved in classical sensitization.

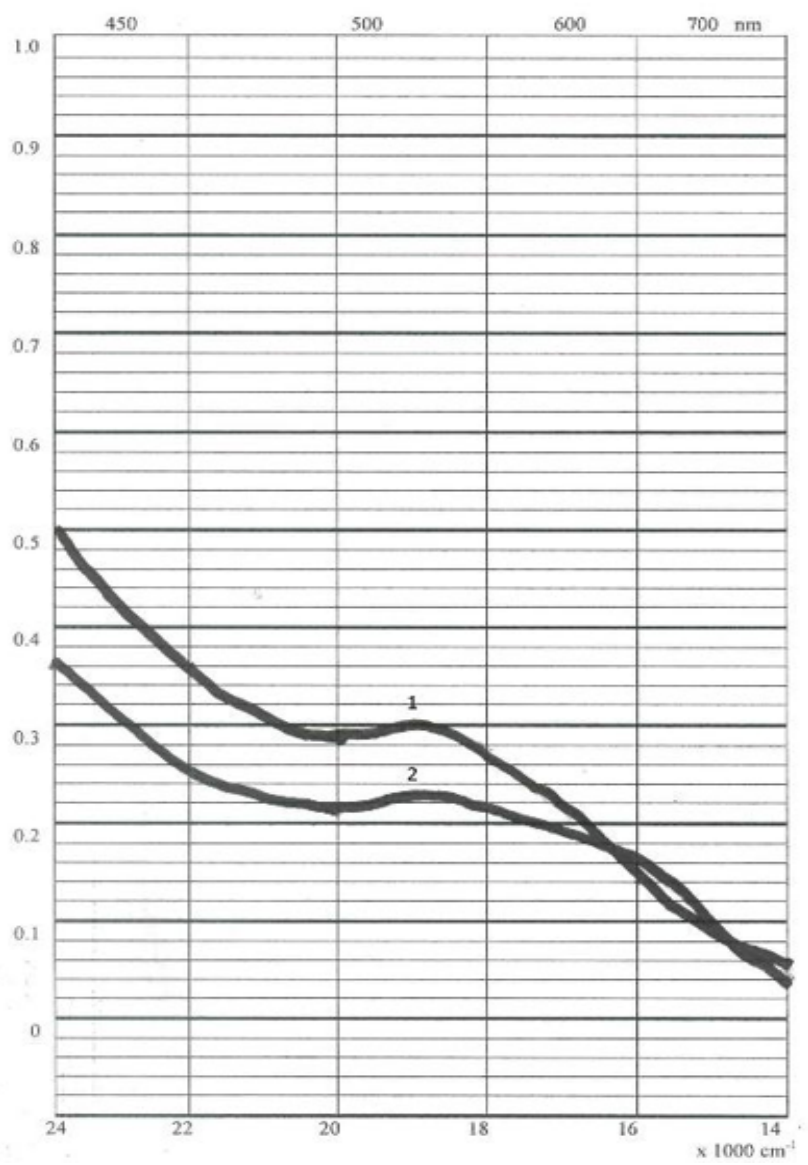

Fig. 1. VIS spectra of gold sulfide nanoparticles suspension obtained from $\mathrm{Na} 2 \mathrm{~S}$ and $\mathrm{HAuCl} 4$ (1) and from $\mathrm{Na} 2 \mathrm{~S} 2 \mathrm{O} 3$ and $\mathrm{HAuCl} 4$ (2)

\section{Preparing the sensitizer}

We prepared several types of nanometric suspensions of $\mathrm{Ag}, \mathrm{Au}, \mathrm{Cu}, \mathrm{Rh}, \mathrm{Pd}, \mathrm{Pt}$, Ir and $\mathrm{Hg}$ sulfide, $\mathrm{Ag}$ and $\mathrm{Au}$ selenide, Ag and Au reduced by precipitation in oxidized gelatin solutions as protective colloid. The concrete working conditions are shown in Table 1. The obtained suspensions were transformed in gel by slow cooling to about $4{ }^{\circ} \mathrm{C}$. After $24 \mathrm{~h}$, the gel was crushed as $5-6 \mathrm{~mm}$ cubes and washed with cold demineralized water (4 to $8^{\circ} \mathrm{C}$ ) to remove soluble reaction compounds, impurities from gelatin, or non-exhausted reactants, until the washing water conductivity remained constant at three successive washings. The washed gel melts at $28-30^{\circ} \mathrm{C}$ under stirring and the final volume is determined (the gel retains a lot of water by swelling). Reduced silver and gold are prepared by both hydroxyl-amine reduction and hydrogen bubbling. UV-Vis absorption spectra were plotted for sensitizer suspensions (example Fig.1 and Fig. 2).

\section{Sensitization by preformed sensitizer adsorption}

Nanometric suspensions of sensitizers have been tested on several types of emulsions: monodispersed multistructured iodobromide, tabular and ammonia type. The sensitizer dose, temperature and reaction time (adsorption) were optimized by successive tests starting from usual values of the classical chemical ripening. We give just one example of sensitization by adsorption of preformed sensitization centers compared to classical sensitization. We used a monodispersed multistructured iodobromide emulsion having $6 \% / 1 \% / 0.02 \%$ core-to-shell iodide distribution, an average granulation of $0.72 \mu$ and a coefficient of variation (defined as the ratio between mean square deviation and mean size) of $0.12 \%$ (Fig. 3) To 15

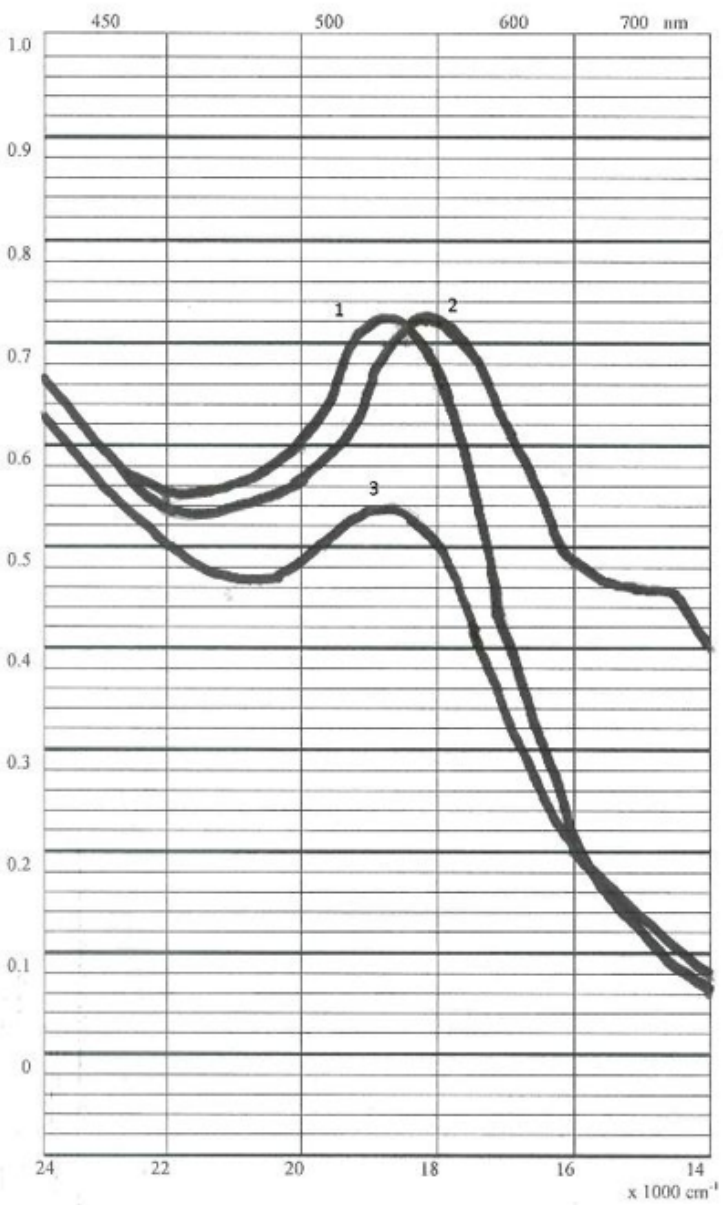

Fig. 2. VIS spectra of gold sulfide nanoparticles suspensions obtained from $\mathrm{Na} 2 \mathrm{~S}$ and $\mathrm{H} \mathrm{AuCl} 4$ (1), from Na2S2O3 and $\mathrm{HAuCl} 4$ (2) and silver sulfide from $\mathrm{Na} 2 \mathrm{~S} 2 \mathrm{O} 3$ and $\mathrm{HAuCl} 4$ (3) 


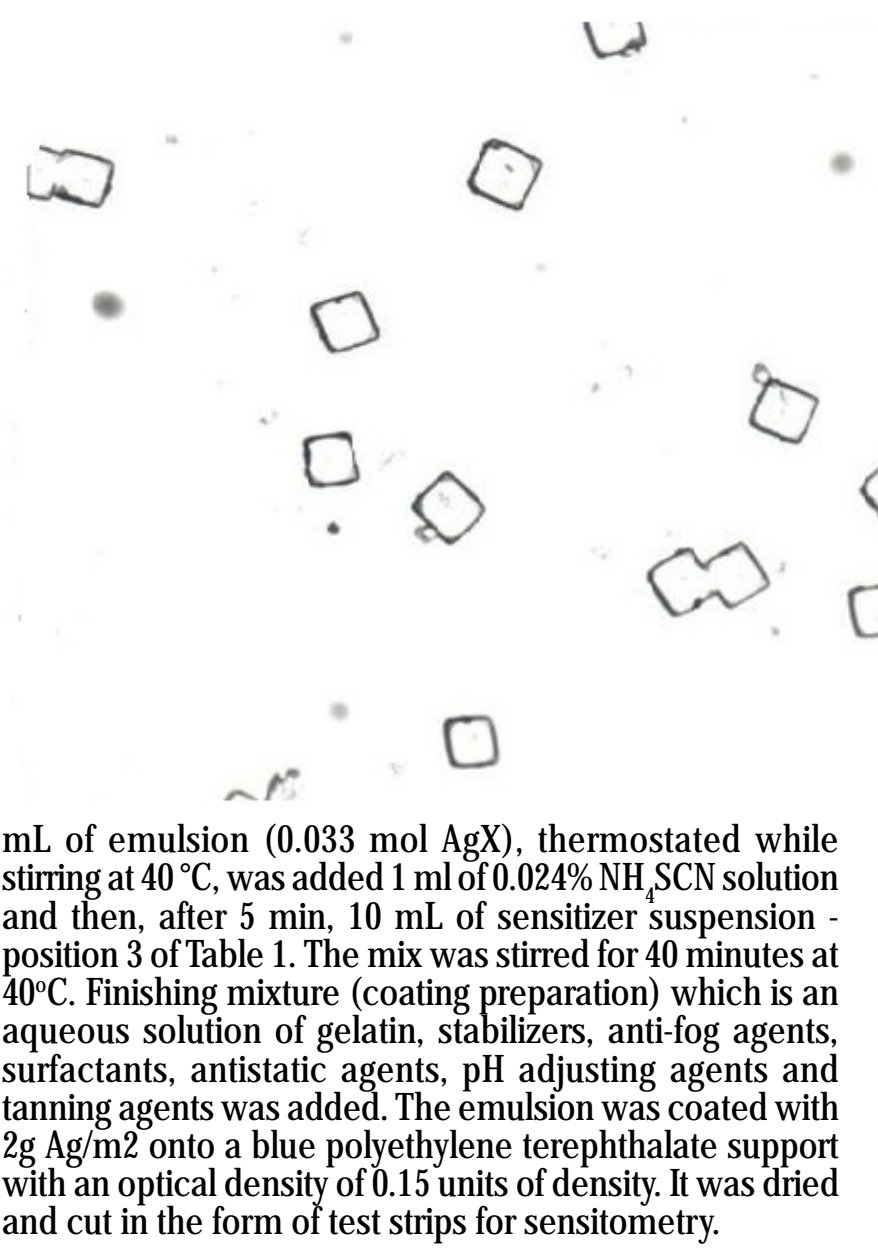

Fig.3. Transmission electron micrograph of the used monodispersed multistructured iodobromide emulsion

Classical sensitization (control)

To $15 \mathrm{~mL}$ of emulsion (the same as the previous sample), thermostated with stirring at $47^{\circ} \mathrm{C}$, was added $9 \mathrm{~mL}$ of a solution containing $1.3 \%$ gelatin and $0.05 \% \mathrm{KBr}$, then $9 \mathrm{~mL}$ of a sensitizer solution containing $0.002 \%$ tetrachloroauric acid, $07 \%$ sodium thiosulfate and $0.02 \%$ ammonium thiocyanate. Emulsion samples were taken after 40, 60, 80 and 100 minutes, which were treated above.

\section{Sensitometric processing}

The sensitometric test strips were exposed in a Sakuratype sensitometer, calibrated for color temperature and

Table 1

EXPERIMENTAL CONDITIONS FOR THE PREPARATION OF PREFORMED NANOSCALE SENSITIZERS

\begin{tabular}{|c|c|c|c|c|c|c|}
\hline No & Coloid protector & Non-metallic element source & $\begin{array}{l}\text { Metallic element } \\
\text { source }\end{array}$ & $\begin{array}{l}\text { Temperature } \\
{\left[{ }^{\circ} \mathrm{C}\right]}\end{array}$ & $\begin{array}{l}\text { Time } \\
\text { [minutes] }\end{array}$ & $\begin{array}{l}\text { Composition } \\
\text { of } \\
\text { nanoparticles }\end{array}$ \\
\hline 1 & $\begin{array}{l}450 \mathrm{ml} \text { sol. } \\
\text { Gelatin } 0.5 \%\end{array}$ & $\begin{array}{l}18 \mathrm{ml} \text { sol. } 0.16 \% \\
\mathrm{Na}_{2} \mathrm{~S}_{2} \mathrm{O}_{3}\end{array}$ & $\begin{array}{l}40 \mathrm{ml} \text { sol. } 0.05 \% \\
\mathrm{HAuCl}_{4}\end{array}$ & 50 & 75 & $\mathrm{Au}_{2} \mathrm{~S}$ \\
\hline 2 & idem & idem & $\begin{array}{l}40 \mathrm{ml} \text { sol. } 0.05 \% \\
\mathrm{AgNO}_{3}\end{array}$ & idem & idem & $\mathrm{Ag}_{2} \mathrm{~S}$ \\
\hline 3 & $\begin{array}{l}300 \mathrm{ml} \text { sol. } 5 \% \\
\text { gelatin }\end{array}$ & $\begin{array}{l}17 \mathrm{ml} \text { sol. } 0.05 \% \\
\mathrm{Na}_{2} \mathrm{~S}\end{array}$ & $\begin{array}{l}80 \mathrm{ml} \text { sol. } 0.16 \% \\
\mathrm{NH}_{4}\left[\mathrm{Au}(\mathrm{SCN})_{2}\right]\end{array}$ & Idem & 70 & $\mathrm{Au}_{2} \mathrm{~S}$ \\
\hline 4 & idem & idem & $\begin{array}{l}100 \mathrm{ml} \text { sol. } 0.2 \% \\
\mathrm{AgNO}_{3}\end{array}$ & idem & idem & $\mathrm{Ag}_{2} \mathrm{~S}$ \\
\hline 5 & $\begin{array}{l}400 \mathrm{ml} \text { sol. } \\
3.75 \% \text { gelatin }\end{array}$ & $\mathrm{H}_{2}$ & $\begin{array}{l}100 \mathrm{ml} \text { sol. } 0.24 \% \\
{\left[\mathrm{Ag}\left(\mathrm{NH}_{3}\right)_{2}\right] \mathrm{NO}_{3}}\end{array}$ & idem & 15 & Ag metallic \\
\hline 6 & $\begin{array}{l}275 \mathrm{ml} \text { sol. } 11 \% \\
\text { gelatin }\end{array}$ & $\begin{array}{l}90 \mathrm{ml} \text { sol. } 0.1 \% \text { hydroxylamine } \\
\text { sulfate }\end{array}$ & $\begin{array}{l}135 \mathrm{ml} \mathrm{sol.0.2 \%} \\
\mathrm{HAuCl}_{4}\end{array}$ & idem & 50 & Au metallic \\
\hline 7 & $\begin{array}{l}383 \mathrm{ml} \mathrm{sol.} 8 \% \\
\text { gelatin }\end{array}$ & $17 \mathrm{ml}$ sol. $0.05 \% \mathrm{Na}_{2} \mathrm{~S}$ & $\begin{array}{l}100 \mathrm{ml} \text { sol. } 0.15 \% \\
\mathrm{CuCl}_{2}\end{array}$ & idem & 70 & CuS, $\mathrm{Cu}_{2} \mathrm{~S}$ \\
\hline 8 & $\begin{array}{l}473 \mathrm{ml} \text { sol. } 6.4 \% \\
\text { gelatin }\end{array}$ & idem & $10 \mathrm{ml} \mathrm{sol.1 \%} \mathrm{RhCl}_{3}$ & idem & idem & $\mathrm{Rh}_{2} \mathrm{~S}_{3}$ \\
\hline 9 & $\begin{array}{l}360 \mathrm{ml} \text { sol. } \\
8.33 \% \text { gelatin }\end{array}$ & $\begin{array}{l}40 \mathrm{ml} \mathrm{sol.} \mathrm{H}_{2} \mathrm{Se} \text { saturated at } \\
\text { room temperature }\end{array}$ & $\begin{array}{l}100 \mathrm{ml} \text { sol. } 0.2 \% \\
\mathrm{AgNO}_{3}\end{array}$ & idem & idem & $\mathrm{Ag}_{2} \mathrm{Se}$ \\
\hline 10 & idem & idem & $\begin{array}{l}78.2 \mathrm{ml} \text { sol. } 0.2 \% \\
\mathrm{HAuCl}_{4}\end{array}$ & idem & idem & $\mathrm{Au}_{2} \mathrm{Se}$ \\
\hline 11 & $\begin{array}{l}383 \mathrm{ml} \mathrm{sol.} 8 \% \\
\text { gelatin }\end{array}$ & $\begin{array}{l}17 \mathrm{ml} \text { sol. } 0.05 \% \\
\mathrm{Na}_{2} \mathrm{~S}\end{array}$ & $100 \mathrm{ml}$ sol. $0.21 \% \mathrm{PdCl}_{2}$ & idem & idem & $\mathrm{PdS}$ \\
\hline 12 & idem & idem & $\begin{array}{l}100 \mathrm{ml} \mathrm{sol} .0 .6 \% \\
\left.\mathrm{~K}_{2}[\mathrm{PtCl}]_{6}\right]\end{array}$ & idem & idem & PtS \\
\hline 13 & idem & idem & $\begin{array}{l}100 \mathrm{ml} \text { sol. } 0.35 \% \\
\mathrm{HgCl}_{2}\end{array}$ & idem & idem & $\mathrm{HgS}$ \\
\hline 14 & idem & idem & $\begin{array}{l}100 \mathrm{ml} \mathrm{sol} .0 .1 \% \\
\mathrm{~K}_{2}\left[\mathrm{IrCl}_{6}\right]\end{array}$ & idem & idem & $I r_{2} S_{3}$ \\
\hline
\end{tabular}




\begin{tabular}{|l|l|l|l|l|}
\hline Type of sensitivity & Minimum density & Maximum density & Sensitivity $^{3}$ & Contrast $^{4}$ \\
\hline $\begin{array}{l}\text { Nanoparticle } \\
\text { adsorption }\end{array}$ & 0.16 & 5.01 & 50 & 11.1 \\
\hline Classic & 0.16 & 5.03 & 18 & 3.57 \\
\hline
\end{tabular}

Table 2

COMPARATIVE SENSITOMETRIC RESULTS

1 - Density in the absence of exposure,2 - Maximum exposure density, 3 - Reversal of

exposure required to achieve a density of 0.2 above the minimum density,

4 - The slope of the straight line joining the density points 1 and 2 on the characteristic curve.

illumination intensity, through a sensitometric wedge with 21 steps of blackening, to 3.2 CMS, were developed in a sensitometry developer [27], fixed, washed and dried. Blackening density steps were read with the densitometer, and characteristic curves (blackening density function of exposure logarithm) were represented. The density of the fog (minimum density minus the density of the support), the sensitivity (the inverse of the exposure to achieve a density of 0.2 over the minimum density), and the contrast gradient (the slope of the line joining the density points 1 and 2) were determined.

\section{Results and discussions} found:

As a result of the tests carried out, the following were

-gold, silver, gold and silver, palladium, platinum, rhodium, iridium and copper sulfides sensitize;

-the best sensitizer is the one based on gold sulfide, the weakest is the copper sulfide;

-it is of little importance from what precursor these sulfides have been obtained - sodium sulfide or sodium thiosulfate, tetrachloroauric acid or ammonium dithiocyanato-aurate, cupric or cuprous chloride;

-the size of the sensitizer nanoparticles is important; as its increases, is observed by changing the color and displacement of the maximum absorption in the UV-VIS spectrum to higher wavelengths, the sensitivity and contrast obtained decrease, increases the fog and, over a limit, appears a yellow-brown stain that could be attributed to a physical development directly on sensitivity microcenters not adsorbed on AgX granules. The different behaviors of sensitivity centers according to their size were proposed by E. Miosar [24];

-sensitizer suspensions have good stability; however, after 15 to 20 days they behave as if the size of nanoparticles had increased (possibly coalescence agglomeration or Ostwald maturation [28]);

- mercury sulfide suspensions do not sensitize but produce a strong yellow-brown stain;

- suspensions of silver selenide and gold selenide give a strong fog, but do not give a yellow stain; $\mathrm{H}_{2} \mathrm{Se}$ introduced to classical maturation leads to completely fogging;

- reduced gold and silver suspensions sensitize very little, but cause fog proportionally to the dose and size of nanoparticles; especially in the case of reduced silver, the yellow-brown stain appears also. The behavior is the same regardless of precious metal precursor (neutral or ammonia silver nitrate, tetrachloroauric acid or ammonium dithiocyanato-aurate) or reducer (hydrogen gas or hydroxylamine sulfate) used in the preparation of the sensitizer. The fogging properties of silver or golden centers were also presented in literature $[29,30]$;

-ammonium thiocyanate introduced in emulsion before the gold sulfide sensitizer clearly enhances sensitization;

-alkaline halides added before the sensitizer reduce the sensitivity proportionally with the dose and depending on the solubility of their salts with the silver;

-organic compounds with high silver halide adsorption capacity such as stabilizers (phenylmercapto-tetrazole, tetraazaindenene, adenine, benzotriazole), dye sensitizers, some surfactants, reduce the sensitivity probably by preventing adsorption of sensitizer nanoparticles;

-the addition of a classical sensitizer (thiosulfate or gold and thiosulfate compounds) along with the preformed nanoparticle does notbring a sensitivity gain but an increase of the fog;

-all types of emulsions tested were sensitized with the preformed nanoparticle sensitizer. In some cases, such as that of the monodispersed, multistructured emulsion presented above, the sensitivity gain, compared to the optimal classical sensitization, was $278 \%$ and the contrast gain of $311 \%$ was quite spectacular (Table 2);

-it is possible to sensitize in different phases of AgX grain growth and with different sensitizers (eg nanoparticles that attract electrons to become latent image centers and others capable of neutralizing positive holes, amplifying latent image formation).

The main result of a large number of tests is the generality of sensitization by adsorption. All types of emulsion tested, regardless of the precipitation method (neutral or ammonia type), the composition or internal structure of the granules (chloride, chlorobromide, iodobromide, uniform or multistructured), crystalline form of presentation (cubic, octahedral, cubo - octahedral, tabular) were sensitized (or fogged). The sensitivity and the induced fog could have no other cause than the adsorption of preformed sensitization centers on the silver halide grains because there is no other sensitizer in the emulsion. This demonstrates that the mechanism of photographic sensitization does not require the reaction of chemical sensitizing agents with silver halide at the surface of the grains, but the adsorption of nanoscale sensitivity (or fog) centers on the grains. The influence of sensitization parameters (temperature, dose, time) on the final results is characteristic for an adsorption phenomenon, and not for a complex reaction. Moreover, D.J. Cash [31] found, following some kinetic studies, the lack of correlation between the velocity of the silver sulfide formation reaction and the actual sensitization, and Corbin [32] demonstrated that silver sulfide is formed very quickly, but not sensitized. In order to increase the sensitivity, it is necessary to heat the emulsion for a certain period of time. It is possible to advance the idea that the classical chemical maturation mechanism consists in the overlapping of the process of formation of the sensitivity or fog centers in the emulsion with their adsorption on the grains. Adsorption can occur throughout the growth of these centers, but maximum sensitivity is given by centers of optimal size, the smallest ones probably do not sensitize, and the largest ones cause fog. Hence the critical character of the reaction parameters in the case of classical sensitization.

If, in the case of classical sensitization, the optimal working conditions for the sensitizer dose, the temperature and the time have critical values to be determined experimentally for each emulsion batch, very small deviations leading to at least disturbing effects, in case of sensitization by adsorption of the preformed sensitizer the approach changes. Instead of fixed values, we speak of sufficient values. The dose of the sensitizer should be sufficient to sensitize the maximum percentage of grains. 
If the dose is too high, there are no adverse effects such as rapid fog increase or decrease in sensitivity, maximum density, or contrast. Temperature does not matter much. It must be sufficient to ensure the fluidity of the emulsion. For example, a temperature of $40^{\circ} \mathrm{C}$ is sufficient, and higher values do not bring any gain. The reaction time should also be sufficient to produce the adsorption of the sensitizer nanoparticles on the AgX grains. Since there are no active substances in the emulsion to continue the sensitivity and fog reaction, blocking the process with stabilizers is not critical. Practically, sensitization occurs over $75 \%$ in the first $5 \mathrm{~min}$, but the optimal time was $40 \mathrm{~min}$.

The increase in $\mathrm{pAg}$, and the presence in the emulsion of compounds that strongly adsorb on silver halide, reduce sensitivity both in sensitization by adsorption of the preformed centers and in classical sensitization. The explanation might be to prevent adsorption on the grains.

The addition of classical chemical sensitizers with the preformed nanoscale sensitizer does not increase sensitivity but increases the fog. It means that the grow th process of the sensitizing particles continues, going beyond the optimum. It cannot be discerned whether this increase occurs in the liquid and / or the surface of the grains.

The interesting behavior of gold nanoparticles, but especially of silver ones, which does not sensitize but produce fog, seems to clarify the discussion about the nature of the fog centers compared to the sensitivity centers. Moreover, it seems to argue for the mechanism of transforming the sensitivity center into a development center by capturing $\mathrm{Ag}^{\circ}$.

The present study was limited to testing nanoscale suspensions of compounds known to be active in photographic sensitization, the protective colloid being gelatin. It would be interesting to test preparations in other protective colloids or nanosuspension stabilizers, but especially to broaden the nature of these nanoparticles in the idea of correlating the semiconductor, metallic, or isolating properties with the sensitizing properties. Advanced characterization of nanoparticles (composition, shape, average size, granulometric distribution) correlated with light absorption and sensitizing properties is required.

The authors have experienced empirical research, from the observation of a phenomenon to its characterization $[33,34]$, as well as innovative, fundamental research [35], showing potential to continue this work.

\section{Conclusions}

The first conclusion is that sensitivity or fog centers are nanoparticles that can be prepared separately and, by adsorption on silver halide grains, induce very effective sensitization.

The second very important conclusion is related to the methodology of scientific research. This case illustrates the importance of detaching from the unanimously accepted dogmas, reshaping the issue in a fresh, unexpected way, and usually unacceptable by specialists in the field.

\section{References}

1.TANI T., Photographic Science: Advances in Nanopartcles, J. Aggregates, Dye Sensitization and Organic Devices, Part I Progres in photographic Science, Introduction, Published to OxfordnScholarship Online: J anuary 2012, DOI: 10.1093/acprof:0so/9780199572953,003,0001 2.MOISAR E., Photogr. Sci. Eng., 25, nr. 2, 1981, p.4

3.*** The Focal Encyclopedia of Photography, Desk Edition, London, 1978 (Focal Press), p.1349.

4.BRESLOV YU. A., Zh.Nauch. Prikl. Fotogr. Kinematogr., 15, 1970, p. 458

5.WOOD H.W., Sci. Ind. Photogr., 2, 23, 1952, p. 209

6.WOOD H.W., J. Photogr. Sci., 2, 1954, p. 14

7.BENETT C., Brit. J. Photogr., 25, 1878, p. 146

8.*** Newton H.J ., The Photographyc News, Ian, 9, 1874

9.KOSLOW SKI R, MUELLER F.W.H., Agfa Film Plant, Wollfen, Germany, Reports Sept-Oct. 1936, Bibliogr. Sci. Ind. Reports (U.S. Dept. Com.) Vol 8, PB 70053 p. 873

10.TRIVELLI A.P.H., WISS Z. Phot., 26, 1920, p. 384

11.SHEPARD S.E., Photographyc J., 65, 1925, p. 380

12.HODGSON M.B., J. Franklin Inst. 184, 1917, p. 705

13.SHEPPARD S.E., WIGHTMAN E.P., TRIVELLI A.P.H., J. Franklin Inst., $196,63,1923$, p.779

14SHAPPARD S.E., TRIVELLI A.P.H., LOVELAND R.P., J. Franklin Inst.,200, 1925, p. 51

15.LUPPO-CRAMER H.,Photogr. Mitt., 1909, p. 328

16SHEPPARD S.E., Colloid Symp. Monogr..,3, 1925, p. 76

17.CLARK W., Brit. J. Photogr.,74, 227, 1927, p.243

18.KOSLOWSKI R., Z. Wiss. Photogr. 46, 1951, p. 65

19.MUELLER F. W. H., J. Opt. Soc. Am., 39, 1949, p. 494

20.DICKINSON H.O., J. Photogr. Sci., 7, 1959, p. 105

21.HAUTOT A., SAUVENIER H., Sci. Ind. Photogr., (2)28, 1, 1957, p. 57

22.MUELLER W., Photogr. Sci. Eng., 10, 1966, p. 318

23.FAELENS P., Photogr. Korresp., 104, 1968, p. 137

24.MIOSAR E., J. Photogr. Sci., 14, 181, (1966); ibid., 16, 1968, p. 102

25.MITCHELL J. W., Photogr. Korresp. 1, Sonderheft, 1957, p.1

26.TANI T., J ournal of Dispersion Science and Technology, 25, 4, 2005, 375

27.*** AMERICAN NATIONAL STANDARD PH 2.5 - 1972

28.J AMES T.H., The Theory Of Photographic Process, Fourth Edition, Macmillan Publishing Co., Inc. New York. 1977, pag. 93

29.VANASSCHE W., BORGINON H., PATTYN H., PEELAERS W., MOISAR

E., J. Photogr. Sci., 22, 1974, p. 121

30.TANI T., Photogr. Sci. Eng., 15, 28, 1971, p. 181

31.CASH D. J., J. Photogr. Sci.,20, 77, 1978, p. 223

32.CORBIN D., GINGELLO A., MACINTYRE G., CARROL B.H., Photogr.

Sci. Eng., 24, 1980, p. 45

33.BACAREA, P.F., NEDA I, DANILIUC,C.G., BACAREA, A, SILAGHI

DUMITRESCU, L,, Rev. Chim. (Bucharest), 63, no. 5, 2012, p. 489

34.BACAREA A, TARCEA M, BOTIANU PV, RUTÃ F, BACAREA V, Obes Res Clin Pract. 9, 5, 2015, p. 527

35.BACAREA PETRUS FANEL, BACAREA VLADIMIR CONSTANTIN, BACAREA ANCA , R0129455 (A2) ${ }^{-}$2014-05-30

Manuscript received: 20.03 .2019 